Article

\title{
Density Measurements of Waste Cooking Oil Biodiesel and Diesel Blends Over Extended Pressure and Temperature Ranges
}

\author{
Thanh Xuan NguyenThi ${ }^{1}{ }^{(\mathbb{D}}$, Jean-Patrick Bazile ${ }^{2}$ and David Bessières ${ }^{2, *}$ \\ 1 Department of Chemical Engineering-Petroleum and Gas, The University of Danang-University of Science \\ and Technology, 54 Nguyen Luong Bang, DaNang 550000, Vietnam; nttxuan@dut.udn.vn \\ 2 TOTAL-Laboratoire des Fluides Complexes et leurs Réservoirs, University Pau \& Pays Adour, \\ UMR 5150-LFC-R, CNRS, BP 1155-Pau, F-64013, France; jean-patrick.bazile@univ-pau.fr \\ * Correspondence: david.bessieres@univ-pau.fr
}

Received: 13 April 2018; Accepted: 7 May 2018; Published: 9 May 2018

\begin{abstract}
Density and compressibility are primordial parameters for the optimization of diesel engine operation. With this objective, these properties were reported for waste cooking oil biodiesel and its blends ( $5 \%$ and $10 \%$ by volume) mixed with diesel. The density measurements were performed over expanded ranges of pressure ( 0.1 to $140 \mathrm{MPa}$ ) and temperature ( 293.15 to $353.15 \mathrm{~K}$ ) compatible with engine applications. The isothermal compressibility was estimated within the same experimental range by density differentiation. The Fatty Acid Methyl Esters (FAMEs) profile of the biodiesel was determined using a Gas Chromatography-Mass Spectrometry (GC-MS) technique. The storage stability of the biodiesel was assessed in terms of the reproducibility of the measured properties. The transferability of this biodiesel fuel was discussed on the basis of the standards specifications that support their use in fuel engines. Additionally, this original set of data represents meaningful information to develop new approaches or to evaluate the predictive capability of models previously developed.
\end{abstract}

Keywords: waste cooking oil biodiesel; FAMEs profile; storage stability; density; viscosity

\section{Introduction}

Biodiesel, known as a renewable and environmentally friendly fuel, has attracted the attention of the scientific community over the past decade. Feedstocks for biodiesel production have been studied over three generations. The first generation deals with vegetable oils-traditional edible oil, which may cause the problem of food shortages and agricultural land competition. The debate on the sustainability of this first-generation biodiesel has led to the research of second- and third-generation biodiesels [1]. The second generation of biodiesel consists of agricultural byproducts, waste oil, and animal fats. These are considered to be a promising alternative source for edible plants and in line with each country's regional development strategy [2,3]. This work implemented the second-generation biodiesel issue of waste cooking oil to be used as biodiesel feedstocks. Waste cooking oil (WCO) is a fatty waste from food processing and is no longer suitable for human use. The massive development of tourism services along with food processing chains, especially fast-food chains, and the rise of instant noodle factories in developing countries has led to the discharge of large amounts of WCO. This is becoming a serious environmental problem. WCO released directly into sewage pipes will cause congestion in sewer lines; when entering sewage treatment plants, it generates operational troubles or system overloading because lipids are very difficult to decompose, and are therefore causes of soil and water pollution [4]. Many recent studies on biodiesel production from WCO have revealed the great potential of this feedstock compared with first-generation biodiesel in terms of resolving environmental, economic, and social issues simultaneously [5-10]. 
Considering energy and environmental issues, one of the most important concerns is the fuel injection system which operates at high pressure. The objective here is to introduce the appropriate amount of fuel into the engine in order to enhance the fuel/air mixture combustion [11] for engine efficiency. Calibrated high-pressure injection supposes an accurate knowledge of the thermophysical properties of biodiesel over wide ranges of pressure and temperature. Among them, density is an important parameter that influences the conversion of volume flow rate into mass biodiesel flow rate [12], whereas the compressibility linked to a bulk modulus controls the fuel injection timing [13]. Their knowledge is of importance within the same operating pressure and temperature ranges.

In this context, the present work aims to provide a complete thermophysical characterization of a biodiesel produced from WCO which was procured from a local restaurant in Vietnam. The Fatty Acid Methyl Esters (FAMEs) profile of this biodiesel sample was determined through the use of a GC-MS technique. Additionally, two different fuel blends (5\%, $10 \%$ by volume mixing with base diesel) were studied along with base diesel fuel and pure biodiesel. The diesel was provided by a refinery. The choice of these compositions meets the most common commercial blends today in use. Density measurements were performed for the pure biodiesel and its two blends within broad ranges of pressure ( 0.1 to $140 \mathrm{MPa}$ ) and temperature $(293.15$ to $353.15 \mathrm{~K})$ which meet the operating conditions in engine use. The differentiation of the density measurement allows estimation of the isothermal compressibility in the same pressure and temperature ranges. The reproducibility of the two properties was checked for each sample. This is also an unambiguous indicator of the storage stability of the biodiesel. The paper is organized as follows. Section 2 details the description of the experimental techniques, whereas Section 3 reports all results obtained for the thermophysical properties as well as information on the materials' composition. The potential use of this fluid as biodiesel is discussed on the basis of this experimental study.

\section{Experimental Techniques}

\subsection{WCO Biodiesel Preparation and FAME Analysis Method}

\subsubsection{WCO Biodiesel Synthesis}

The WCO used as a feedstock for biodiesel synthesis in this study was procured from a local restaurant in Vietnam. The WCO sample was obtained by the way of collection after being used once for cooking various dishes and then filtered to remove any inorganic residues and suspended matter. The first phase of the study concerned the analysis of the WCO sample. Some of its chemical properties—saponification value, acid value, and Iodine number-were determined as $192.64 \mathrm{mg}$ $\mathrm{KOH} / \mathrm{g}$, $3.96 \mathrm{mg} \mathrm{KOH} / \mathrm{g}$, and $87.76 \mathrm{~g} \mathrm{I}_{2} / 100 \mathrm{~g}$, respectively (Table 1).

Table 1. Main properties of the analyzed WCO.

\begin{tabular}{ccc}
\hline Property & Units & Average Value \\
\hline Saponification value & $\mathrm{mg} \mathrm{KOH} / \mathrm{g}$ & 192.64 \\
Acid value & $\mathrm{mg} \mathrm{KOH} / \mathrm{g}$ & 3.96 \\
Iodine number & $\mathrm{g} \mathrm{I}_{2} / 100 \mathrm{~g}$ & 87.76 \\
\hline
\end{tabular}

Taking into consideration the average acid value of $3.96 \mathrm{mg} \mathrm{KOH} / \mathrm{g}$, corresponding to the weight percent of Free Fatty Acid (\%FFA) lower than 2\%, the methods used for biodiesel production from WCO are very similar to the conventional transesterification process with an alkali catalyst. The transesterification procedure was carried out following the steps detailed in the research of Basak Burcu Uzun et al. [14] at optimized conditions such as a methanol/oil molar ratio of 7:1, a reaction time of $30 \mathrm{~min}$, and a reaction temperature of $50{ }^{\circ} \mathrm{C}$ in the presence of $\mathrm{NaOH}$ catalyst at a concentration of $0.5 \mathrm{wt} \%$. At the end of the reaction, the product mixture was poured into a separating funnel, and left overnight to cool down and for separation of phases. After removing the 
lower phase which contained the glycerol, remaining catalyst, extra methanol, and undesired products, we received the upper phase consisting of methyl esters and lower concentrations of catalyst, glycerol, and methanol. This ester layer was washed several times with a small amount of hot distilled water each time until the washings were neutral. The washed methyl esters were then dried under vacuum and weighed to find the biodiesel yields.

\subsubsection{FAMEs Analysis}

The FAMEs in biodiesel prepared from WCO were estimated using a Thermo Scientific ${ }^{\mathrm{TM}} \mathrm{ISQ}^{\mathrm{TM}}$ LT Single Quadrupole GC-MS System (Thermo Fisher Scientific, Waltham, MA, USA). The column used was a Thermo Scientific ${ }^{\mathrm{TM}}$ Trace GOLD TG-5MS Column with dimensions of $0.25 \mu \mathrm{m}$ thickness, $0.25 \mathrm{~mm}$ ID, $30 \mathrm{~m}$ length. This Thermo Scientific TraceGOLD TG-5MS column is a low-polarity, $5 \%$ diphenyl/95\% dimethyl polysiloxane column which is ideal for most Gas Chromatography applications. This phase gives extremely low bleed and has a maximum operating temperature of $350{ }^{\circ} \mathrm{C}$. The oven temperature was initially held at $160{ }^{\circ} \mathrm{C}$ for $2 \mathrm{~min}$, increased to $180^{\circ} \mathrm{C}$ at $2{ }^{\circ} \mathrm{C} / \mathrm{min}$ and held for $2 \mathrm{~min}$, increased continuously to $250^{\circ} \mathrm{C}$ at $10^{\circ} \mathrm{C} / \mathrm{min}$, and then held for $2 \mathrm{~min}$. The injector, transfer, and source temperatures were $250^{\circ} \mathrm{C}, 260^{\circ} \mathrm{C}$, and $240^{\circ} \mathrm{C}$, respectively. The carrier gas was helium and the total scan time was $24 \mathrm{~min}$. The EI mode of ionization was applied and the mass scan range was from 50 to $450 \mathrm{~m} / \mathrm{z}$. GC-MS solution Xcalibur software was used for data processing. For identification of FAMEs, a library search was carried out using National Institute of Standards and Technology (NIST), National Bureau of Standards (NBS), and Wiley GC-MS libraries. The individual peaks of the gas chromatogram were analyzed and the fatty acids were identified using the MS database. The relative percentage of fatty acid esters was calculated from total ion chromatography by a computerized integrator.

\subsection{High-Pressure Density Measurement}

Density was measured as a function of pressure and temperature using an ANTON-PAAR vibrating tube densimeter (Anton Paar $\mathrm{GmbH}$, Graz, Austria) equipped with a high-pressure cell (DMA HPM). This high-pressure densimeter cell enables measurements over broad ranges of pressure ( 0.1 to $140 \mathrm{MPa})$ and temperature $(283.15$ to $403.15 \mathrm{~K})$. The well-known measurement principle consists of determining the oscillation period of a U-shaped tube which contains the sample. The square of this period is correlated to the density through a linear relationship. The parameters of this linear law were determined using water and decane as a reference liquid. This calibration procedure has been largely detailed elsewhere. For examples, see the works of Lagourette et.al. [15], Miyake et.al. [16], and Pineiro et.al. [17]. The estimated uncertainty of the measured temperature is $\pm 0.01 \mathrm{~K}$ between (293.15 and $353.15 \mathrm{~K}$ ) (Anton Paar MKT50 thermometer) while the estimated uncertainty of the measured pressure is $\pm 0.015 \mathrm{MPa}$ (Presents Precise Gold Plus pressure transmitter); as a consequence, the uncertainty on the density measurement is estimated to be $\pm 0.5 \mathrm{~kg} \mathrm{~m}^{-3}$ (i.e., around $0.05 \%$ for density close to that of water). This uncertainty is similar to that reported in several other studies [14-17].

\section{Results and Discussion}

\subsection{Fresh Biodiesel: Relative Compositions of Fatty Acid Contents}

The fatty acid profile of the biodiesel prepared from waste cooking oil is presented in Figure 1.

The relative percentage of fatty acid esters was calculated from total ion chromatography by a computerized integrator, and the results are presented in Table 2.

Oleic acid (C18:1) and palmitic acid (C16:0) are the major fatty acids in WCO biodiesel with $37.59 \mathrm{wt} \%$ and $25.14 \mathrm{wt} \%$, respectively, followed by stearate acid (C18:0, $13.18 \mathrm{wt} \%$ ), linoleic acid (C18:2, 9.76 wt \%), and palmitoleic acid (C16:1, $7.16 \mathrm{wt} \%)$. The long-chain fatty acids are present as minor constituents. This result conforms with those of the investigation conducted by Leung and Guo [18] 
who synthesized biodiesel from used frying oil collected from local Chinese restaurants. The study by Huseyin Sanli et al. [19] conducted on 35 samples taken from different facilities producing waste frying oils (fast foods, fish restaurants, and hospital restaurants) resulted in equivalent FAMEs profiles, especially for the samples from fast foods and fish restaurants. Their FAME analysis showed that the fatty acids of these biodiesels were composed primarily of oleic acid and palmitic acid, followed by linoleic acid. These components are able to improve not only certain important fuel properties like cetane number, heat of combustion, oxidative stability, and kinematic viscosity (C18:1, C16:0), but also the cold flow properties of biodiesel (C18:2) as shown in the works of Knothe G. [20] Based on this profile of fatty acid composition, it is clearly assumed that waste cooking oil is suitable for biodiesel production. The storage stability of the sample was then checked.

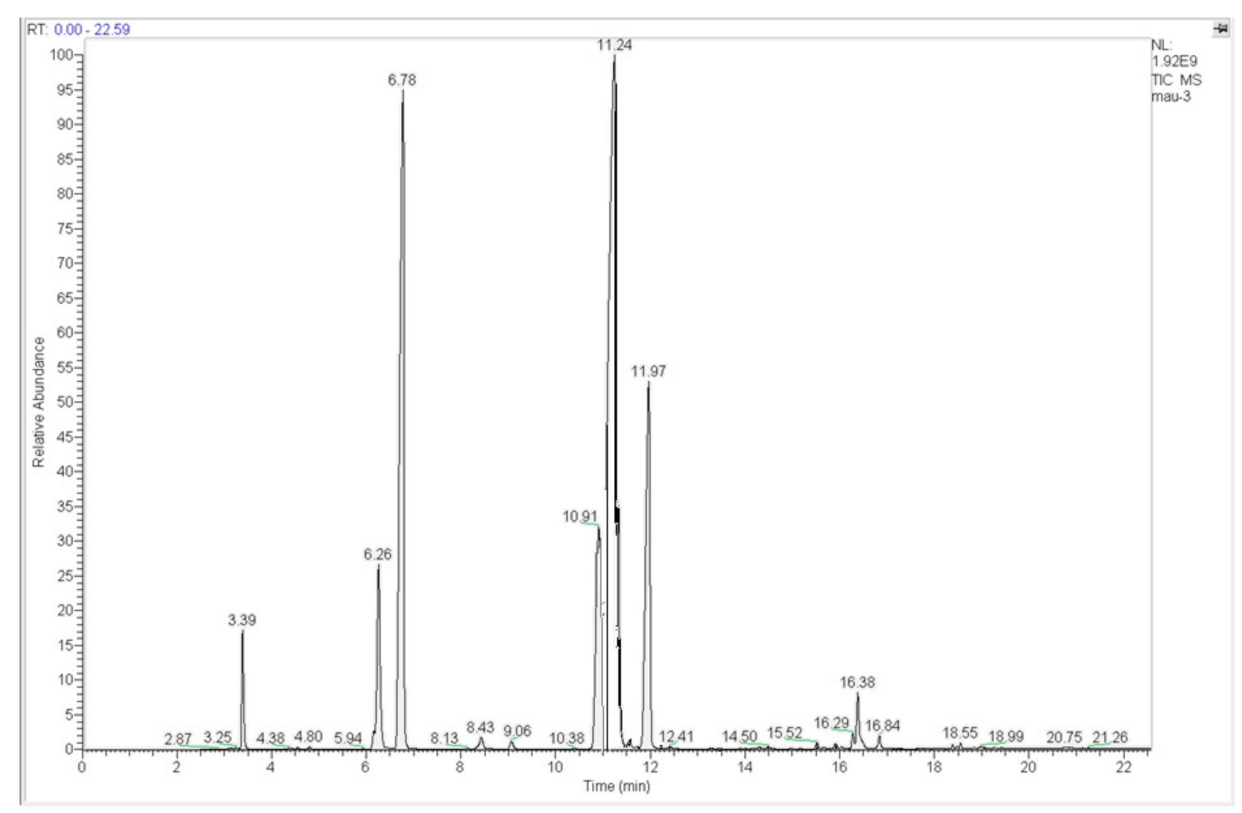

Figure 1. Gas chromatogram of biodiesel from waste cooking oil.

Table 2. Fatty Acid Methyl Ester (FAME) profile of the WCO biodiesel (in terms of relative weight percentage).

\begin{tabular}{ccc}
\hline Retention Time (min) & FAME & wt \% \\
\hline 3.39 & Methyl myristate (C14:0) & 3.22 \\
6.26 & Methyl palmitoleate (C16:1) & 7.16 \\
6.78 & Methyl palmitate (C16:0) & 25.14 \\
10.91 & Methyl linoleate (C18:2) & 9.76 \\
11.24 & Methyl oleate (C18:1) & 37.59 \\
11.97 & Methyl stearate (C18:0) & 13.18 \\
16.29 & Methyl eicosadienoate (C20:2) & 0.53 \\
16.38 & Methyl eicosenoate (C20:1) & 1.77 \\
16.84 & Methyl eicosanoate (C20:0) & 0.62 \\
\hline
\end{tabular}

Previous to any experimental measurement, the stability of the fresh biodiesel sample was checked. In this study, the oxidative or storage stability was assessed through the reproducibility of the density and viscosity measurements, knowing that such properties are clearly affected by a modification of the FAMEs profile due to oxidation processes. The methodology followed here consists of replicating density measurements at $0,8,12$, and 24 weeks. For both properties, the reproducibility observed was within the allowed uncertainty range, thus supporting the transferability of the biodiesel. Note that the oxidative stability of a biodiesel produced from waste fish oil was extensively studied in a recent work reported in the literature [21]. 


\subsection{Density Measurements}

Density measurements were carried out along various isotherms spaced at $20 \mathrm{~K}$ intervals (from 293.15 to $353.15 \mathrm{~K}$ ) and for pressures (ranging from 0.1 to $140 \mathrm{MPa}$ ) in steps of $10 \mathrm{MPa}$. This experimental range was fully described without the appearance of solid deposition which is a good indicator in terms of the cold properties of this biodiesel. The original experimental density data are listed in Table 3 for the waste cooking oil biodiesel (B100) and its blends with diesel containing 5 and 10 vol \% biodiesel, named B5 and B10, respectively. We recall that the uncertainty is estimated to be $0.5 \times 10^{-3} \mathrm{~g} / \mathrm{cm}^{3}$. In this study we are interested in the blends of 5 and $10 \mathrm{vol} \%$ biodiesel based on Vietnam's fuel use.

Table 3. Experimental densities, $\rho$, of WCO biodiesel (B100) and pure diesel (B0) as well as the blends of biodiesel and diesel (B5 and B10) at various temperatures $\mathrm{T}$ and pressures $\mathrm{P}$.

\begin{tabular}{|c|c|c|c|c|}
\hline & \multicolumn{4}{|c|}{$\mathrm{T}(\mathrm{K})$} \\
\hline & 293.15 & 313.15 & 333.15 & 353.15 \\
\hline P (MPa) & \multicolumn{4}{|c|}{$\rho\left(\mathrm{g} \cdot \mathrm{cm}^{-3}\right)$} \\
\hline \multicolumn{5}{|c|}{ B100 } \\
\hline 0.1 & 0.9164 & 0.9022 & 0.8891 & 0.8755 \\
\hline 10 & 0.9216 & 0.9078 & 0.8952 & 0.8824 \\
\hline 20 & 0.9266 & 0.9127 & 0.9012 & 0.8888 \\
\hline 30 & 0.9314 & 0.9183 & 0.9065 & 0.8948 \\
\hline 40 & 0.9359 & 0.9232 & 0.9117 & 0.9002 \\
\hline 50 & 0.9403 & 0.9279 & 0.9165 & 0.9054 \\
\hline 60 & 0.9444 & 0.9322 & 0.9212 & 0.9103 \\
\hline 70 & 0.9485 & 0.9365 & 0.9258 & 0.9149 \\
\hline 80 & 0.9523 & 0.9407 & 0.9300 & 0.9195 \\
\hline 90 & 0.9560 & 0.9445 & 0.9342 & 0.9238 \\
\hline 100 & 0.9601 & 0.9485 & 0.9381 & 0.9281 \\
\hline 110 & 0.9642 & 0.9520 & 0.9419 & 0.9320 \\
\hline 120 & 0.9682 & 0.9554 & 0.9456 & 0.9359 \\
\hline 130 & 0.9721 & 0.9588 & 0.9491 & 0.9396 \\
\hline 140 & 0.9760 & 0.9621 & 0.9526 & 0.9431 \\
\hline \multicolumn{5}{|c|}{ B0 } \\
\hline 0.1 & 0.8325 & 0.8183 & 0.8044 & 0.7897 \\
\hline 10 & 0.8388 & 0.8250 & 0.8117 & 0.7982 \\
\hline 20 & 0.8444 & 0.8312 & 0.8185 & 0.8057 \\
\hline 30 & 0.8498 & 0.8371 & 0.8250 & 0.8127 \\
\hline 40 & 0.8548 & 0.8425 & 0.8309 & 0.8191 \\
\hline 50 & 0.8596 & 0.8475 & 0.8366 & 0.8250 \\
\hline 60 & 0.8640 & 0.8525 & 0.8417 & 0.8304 \\
\hline 70 & 0.8683 & 0.8570 & 0.8466 & 0.8356 \\
\hline 80 & 0.8724 & 0.8614 & 0.8510 & 0.8404 \\
\hline 90 & 0.8763 & 0.8657 & 0.8555 & 0.8452 \\
\hline 100 & 0.8801 & 0.8698 & 0.8598 & 0.8497 \\
\hline 110 & 0.8837 & 0.8737 & 0.8639 & 0.8539 \\
\hline 120 & 0.8875 & 0.8773 & 0.8678 & 0.8580 \\
\hline 130 & 0.8908 & 0.8807 & 0.8716 & 0.8621 \\
\hline 140 & 0.8942 & 0.8842 & 0.8751 & 0.8658 \\
\hline \multicolumn{5}{|c|}{ B5 } \\
\hline 0.1 & 0.8368 & 0.8225 & 0.8089 & 0.7943 \\
\hline 10 & 0.8427 & 0.8290 & 0.8161 & 0.8024 \\
\hline 20 & 0.8484 & 0.8353 & 0.8228 & 0.8100 \\
\hline 30 & 0.8538 & 0.8410 & 0.8290 & 0.8169 \\
\hline 40 & 0.8587 & 0.8465 & 0.8349 & 0.8231 \\
\hline 50 & 0.8634 & 0.8516 & 0.8405 & 0.8290 \\
\hline
\end{tabular}


Table 3. Cont.

\begin{tabular}{|c|c|c|c|c|}
\hline & \multicolumn{4}{|c|}{$\mathrm{T}(\mathrm{K})$} \\
\hline & 293.15 & 313.15 & 333.15 & 353.15 \\
\hline $\mathrm{P}(\mathrm{MPa})$ & \multicolumn{4}{|c|}{$\rho\left(\mathrm{g} \cdot \mathrm{cm}^{-3}\right)$} \\
\hline 60 & 0.8679 & 0.8564 & 0.8457 & 0.8346 \\
\hline 70 & 0.8722 & 0.8609 & 0.8505 & 0.8397 \\
\hline 80 & 0.8764 & 0.8654 & 0.8550 & 0.8446 \\
\hline 90 & 0.8804 & 0.8696 & 0.8595 & 0.8493 \\
\hline 100 & 0.8844 & 0.8736 & 0.8638 & 0.8538 \\
\hline 110 & 0.8878 & 0.8774 & 0.8679 & 0.8579 \\
\hline 120 & 0.8911 & 0.8812 & 0.8719 & 0.8621 \\
\hline 130 & 0.8947 & 0.8847 & 0.8756 & 0.8661 \\
\hline 140 & 0.8980 & 0.8882 & 0.8791 & 0.8698 \\
\hline \multicolumn{5}{|c|}{ B10 } \\
\hline 0.1 & 0.8413 & 0.8268 & 0.8132 & 0.7989 \\
\hline 10 & 0.8471 & 0.8333 & 0.8203 & 0.8069 \\
\hline 20 & 0.8528 & 0.8395 & 0.8271 & 0.8141 \\
\hline 30 & 0.8580 & 0.8452 & 0.8333 & 0.8211 \\
\hline 40 & 0.8629 & 0.8506 & 0.8392 & 0.8272 \\
\hline 50 & 0.8676 & 0.8557 & 0.8446 & 0.8330 \\
\hline 60 & 0.8721 & 0.8605 & 0.8497 & 0.8386 \\
\hline 70 & 0.8764 & 0.8650 & 0.8545 & 0.8436 \\
\hline 80 & 0.8805 & 0.8695 & 0.8592 & 0.8486 \\
\hline 90 & 0.8844 & 0.8736 & 0.8638 & 0.8533 \\
\hline 100 & 0.8881 & 0.8776 & 0.8679 & 0.8576 \\
\hline 110 & 0.8918 & 0.8814 & 0.8719 & 0.8620 \\
\hline 120 & 0.8955 & 0.8852 & 0.8758 & 0.8661 \\
\hline 130 & 0.8989 & 0.8888 & 0.8795 & 0.8699 \\
\hline 140 & 0.9023 & 0.8922 & 0.8832 & 0.8737 \\
\hline
\end{tabular}

Figure 2 displays the pure biodiesel density as a function of pressure (isothermal curves), whereas in Figure 3 is plotted the variation of density as a function of temperature (isobaric curves). The value of the density extrapolated at $288.15 \mathrm{~K}$ and atmospheric pressure is $0.9192 \mathrm{~g} / \mathrm{cm}^{3}$, which is somewhat higher than that the value of the EN 14214 specifications (upper limit $0.9000 \mathrm{~g} / \mathrm{cm}^{3}$ ), which is one of the standards used.

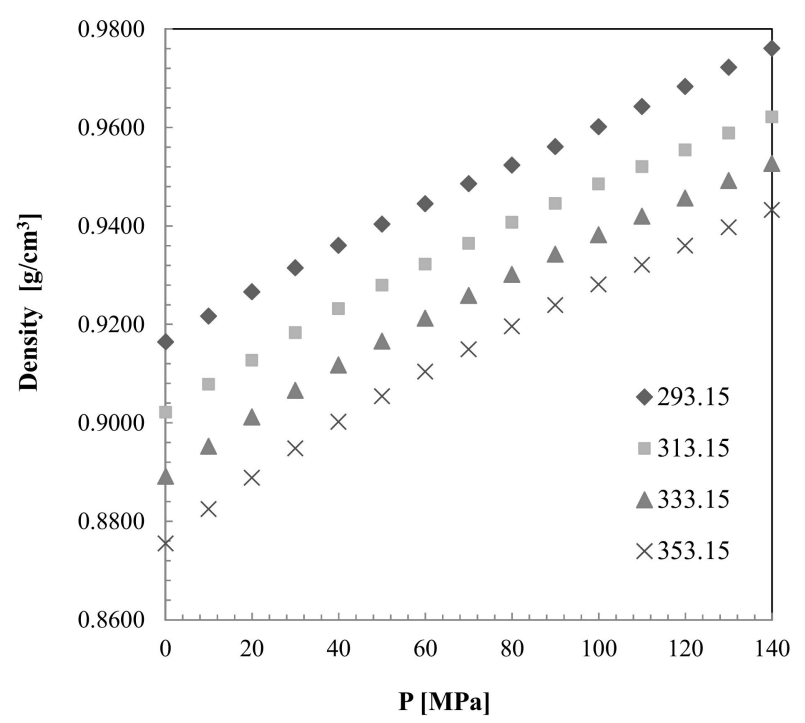

Figure 2. Variation of the WCO biodiesel density as a function of pressure at different temperatures:

• $293.15 \mathrm{~K}, \mathbf{\square} 313.15 \mathrm{~K}, \mathbf{\Delta} 333.15 \mathrm{~K}, \times 353.15 \mathrm{~K}$. 


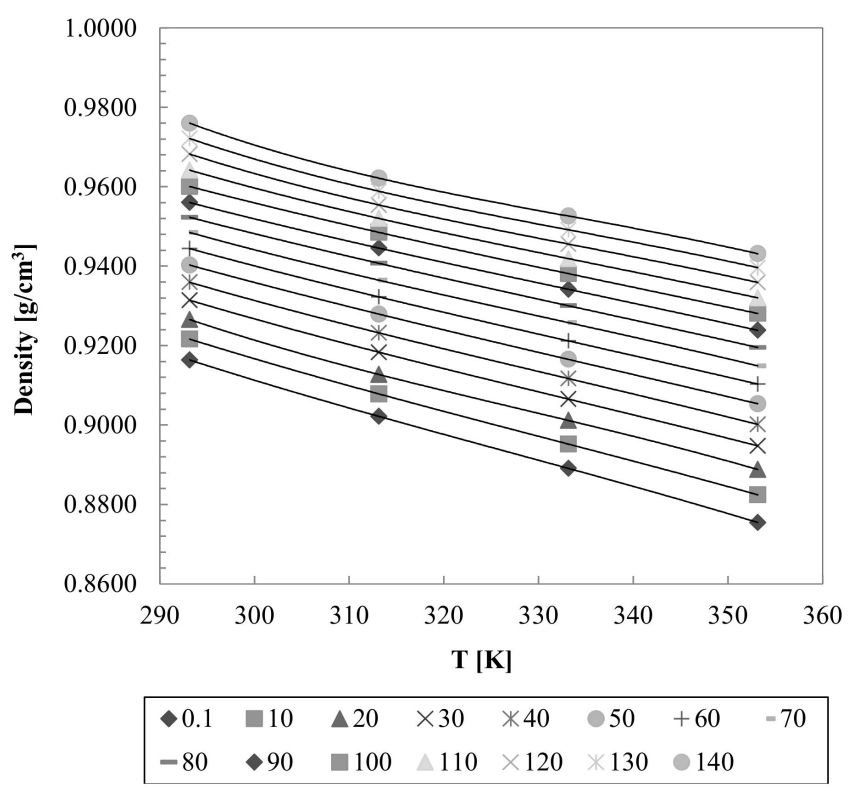

Figure 3. Variation of the fresh biodiesel density as a function of temperature at different pressures (0.1 to $140 \mathrm{MPa})$. (Lines are visual guides.)

Experimental results of the density of biodiesel and its blends with diesel have been plotted in Figure 4 for varying pressure (isothermal curves) at $293.15 \mathrm{~K}$ and in Figure 5 for varying temperature at atmospheric pressure $(0.1 \mathrm{MPa})$. It was found that at a particular pressure/temperature, the lower blend ratio in biodiesel results in lower densities. The diesel is a standard diesel for which the density value is $0.8325 \mathrm{~g} / \mathrm{cm}^{3}$ at $293.15 \mathrm{~K}$ and atmospheric pressure. The density values are very similar to those advised by Ndiaye et al. [11] for a normal fluid designed for fuel engines.

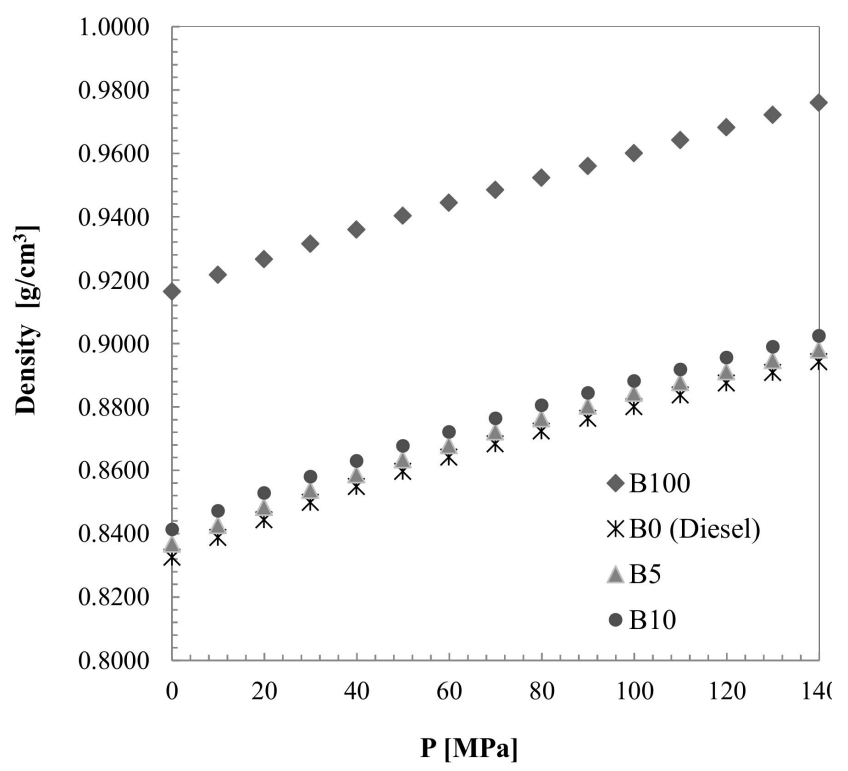

Figure 4. Experimental results of the density of WCO biodiesel (B100), pure diesel (B0), and their blends (B5, B10) for varying pressure (isothermal curves) at $293.15 \mathrm{~K}$. 


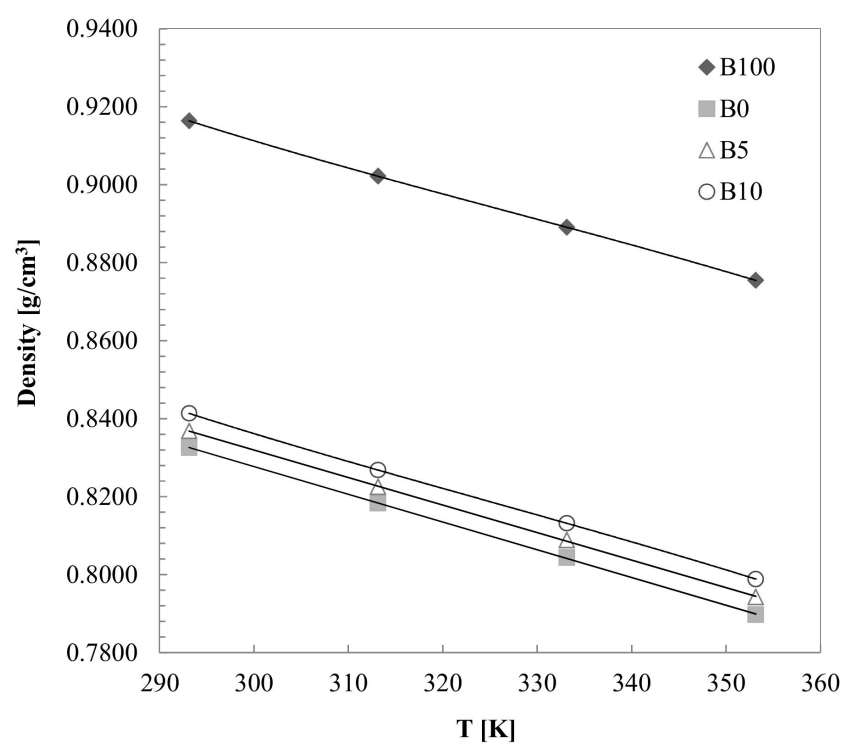

Figure 5. Experimental results of the density of WCO biodiesel (B100), pure diesel (B0), and their blends (B5, B10) for varying temperature (isobar curves) at atmospheric pressure (0.1 $\mathrm{MPa})$.

A modified Tait-like equation was used in order to correlate the density over the entire pressure and temperature ranges:

$$
\rho(\mathrm{P}, \mathrm{T})=\frac{\rho_{0}(T)}{1-\mathrm{Cln} \frac{\mathrm{P}+\mathrm{B}(\mathrm{T})}{0.1+\mathrm{B}(\mathrm{T})}}
$$

in which

$$
\begin{gathered}
\rho_{0}(\mathrm{~T})=\mathrm{A}_{0}+\mathrm{A}_{1} \mathrm{~T}+\mathrm{A}_{2} \mathrm{~T}^{2}+\mathrm{A}_{3} \mathrm{~T}^{3} \\
\mathrm{~B}(\mathrm{~T})=\mathrm{B}_{0}+\mathrm{B}_{1} \mathrm{~T}+\mathrm{B}_{2} \mathrm{~T}^{2}
\end{gathered}
$$

Several indicators allow comparison of the experimental density values with those obtained with the Tait correlation. The absolute average deviation (AAD), the maximum deviation (DMax), the average deviation (Bias), and the standard deviation $(\sigma)$ are defined as follows:

$$
\begin{gathered}
\mathrm{AAD}=\frac{100}{\mathrm{~N}} \sum_{\mathrm{i}=1}^{\mathrm{N}}\left|\frac{\rho_{\mathrm{i}}^{\text {exp }}-\rho_{\mathrm{i}}^{\text {calc }}}{\rho_{\mathrm{i}}^{\text {exp }}}\right| \\
\operatorname{DMax}=\operatorname{Max}\left(100\left|\frac{\rho_{\mathrm{i}}^{\text {exp }}-\rho_{\mathrm{i}}^{\text {calc }}}{\rho_{\mathrm{i}}^{\exp }}\right|\right) \\
\text { Bias }=\frac{100}{\mathrm{~N}} \sum_{\mathrm{i}=1}^{\mathrm{N}} \frac{\rho_{\mathrm{i}}^{\exp }-\rho_{\mathrm{i}}^{\text {calc }}}{\rho_{\mathrm{i}}^{\exp }} \\
\sigma=\sqrt{\frac{\sum_{\mathrm{i}=1}^{\mathrm{N}}\left(\rho_{\mathrm{i}}^{\exp }-\rho_{\mathrm{i}}^{\text {calc }}\right)^{2}}{\mathrm{~N}-\mathrm{m}}}
\end{gathered}
$$

where $\mathrm{N}$ is the number of experimental data ( $\mathrm{N}=60$ for each compound), $\mathrm{m}$ is the number of parameters $\left(\mathrm{m}=8\right.$ in Equation (1)), and $\rho_{\mathrm{i}}^{\text {exp }}$ and $\rho_{\mathrm{i}}^{\text {calc }}$ are the experimental density values of this work and those obtained with Equation (1), respectively. The Tait correlation parameters, along with the AAD, DMax, Bias, and standard deviation $\sigma$, obtained with this correlation are given in Table 4 for the WCO biodiesel (B100), pure diesel (B0), and their blends (B5 and B10). 
Table 4. Obtained parameters and deviations for density correlation by using the Tait equation for WCO biodiesel (B100), pure diesel (B0), and their blends (B5 and B10).

\begin{tabular}{ccccc}
\hline Coefficients & B100 & B0 & B5 & B10 \\
\hline $\mathrm{A}_{0} / \mathrm{g} \cdot \mathrm{cm}^{-3}$ & 2.519378 & 1.662832 & 1.710722 & 1.837863 \\
$\mathrm{~A}_{1} / \mathrm{g} \cdot \mathrm{cm}^{-3} \cdot \mathrm{K}^{-1}$ & -0.013766 & -0.006533 & -0.006947 & -0.008047 \\
$\mathrm{~A}_{2} / \mathrm{g} \cdot \mathrm{cm}^{-3} \cdot \mathrm{K}^{-2}$ & $4.0498 \times 10^{-5}$ & $1.8122 \times 10^{-5}$ & $1.9405 \times 10^{-5}$ & $2.2675 \times 10^{-5}$ \\
$\mathrm{~A}_{3} / \mathrm{g} \cdot \mathrm{cm}^{-3} \cdot \mathrm{K}^{-3}$ & $-4.1607 \times 10^{-8}$ & $-1.8749 \times 10^{-8}$ & $-2.0051 \times 10^{-8}$ & $-2.3271 \times 10^{-8}$ \\
$\mathrm{~B}_{0} / \mathrm{MPa}$ & -22.687549 & 438.128864 & 432.078831 & 480.962920 \\
$\mathrm{~B}_{1} / \mathrm{MPa} \cdot \mathrm{K}^{-1}$ & 1.523006 & -1.576172 & -1.509124 & -1.786701 \\
$\mathrm{~B}_{2} / \mathrm{MPa} \cdot \mathrm{K}^{-1}$ & -0.003194 & 0.001556 & 0.001440 & 0.001858 \\
$\mathrm{C}$ & 0.091540 & 0.083663 & 0.084928 & 0.085788 \\
$\sigma / \mathrm{g} \cdot \mathrm{cm}{ }^{-3}$ & 0.000475 & 0.00011 & 0.000082 & 0.000084 \\
$\mathrm{AAD} / \%$ & $0.03641 \%$ & $0.00936 \%$ & $0.00687 \%$ & $0.00716 \%$ \\
$\mathrm{Dmax} / \%$ & $0.11784 \%$ & $0.02608 \%$ & $0.02830 \%$ & $0.02683 \%$ \\
$\mathrm{Bias} / \%$ & $-0.02453 \%$ & $0.00250 \%$ & $0.00054 \%$ & $-0.00098 \%$ \\
\hline
\end{tabular}

Figures 6 and 7 display the relative deviations between experimental data and calculated densities using the Tait equation as function of pressure for the WCO biodiesel at different temperatures (Figure 6) as well as for all samples at $293.15 \mathrm{~K}$ (Figure 7a) and $353.15 \mathrm{~K}$ (Figure 7b). A careful analysis of this set of data shows very good agreement between experimental values and values obtained from Equation (1) except for pressure ranging from 110 to $140 \mathrm{MPa}$ at $293.15 \mathrm{~K}$. In this specific zone, the deviation increases up to $0.15 \%$, which is somewhat higher than the expected uncertainty. This is probably due to a significant increase in the viscosity of the biodiesel. Using the same technique as in this work, Segovia et al. [22] claim that the uncertainty depends on the experimental ranges, increasing up to $5 \mathrm{~kg} \cdot \mathrm{m}^{-3}$ for highly viscous fluids. Such an increase is explained by the damping effect on the densimeter cell. In the case of our study, the pattern of density is very consistent. We report all the data knowing that uncertainties in the density values for the highest pressures (110 to $140 \mathrm{MPa}$ ) at 293.15 K should be more elevated due to the viscosity effect.

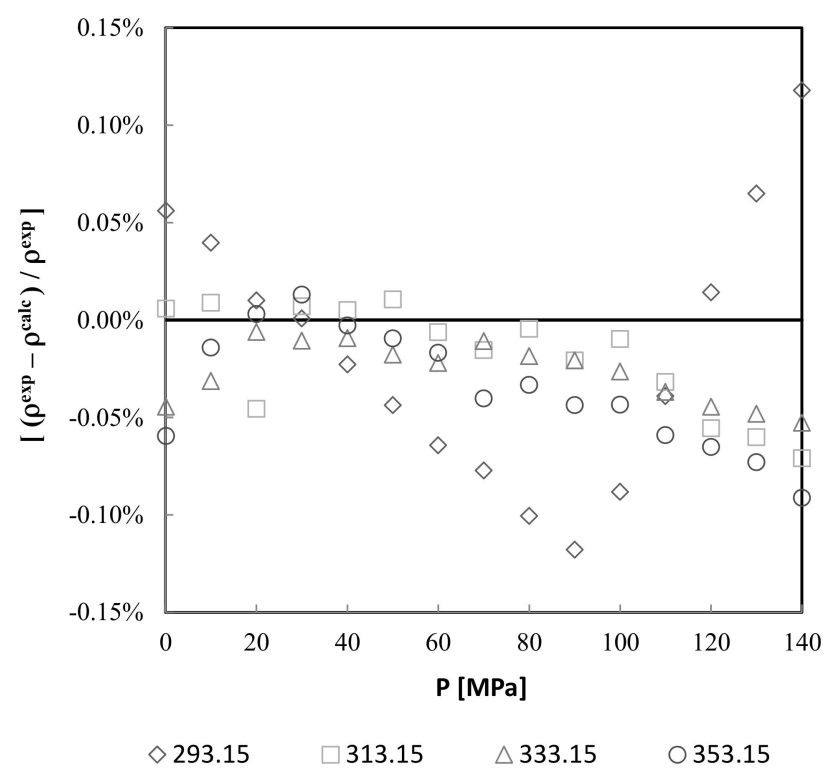

Figure 6. Relative deviations between experimental data and calculated densities using the Tait equation as function of pressure at different temperatures for fresh biodiesel B100. The zero line is experimental data. 




(a)

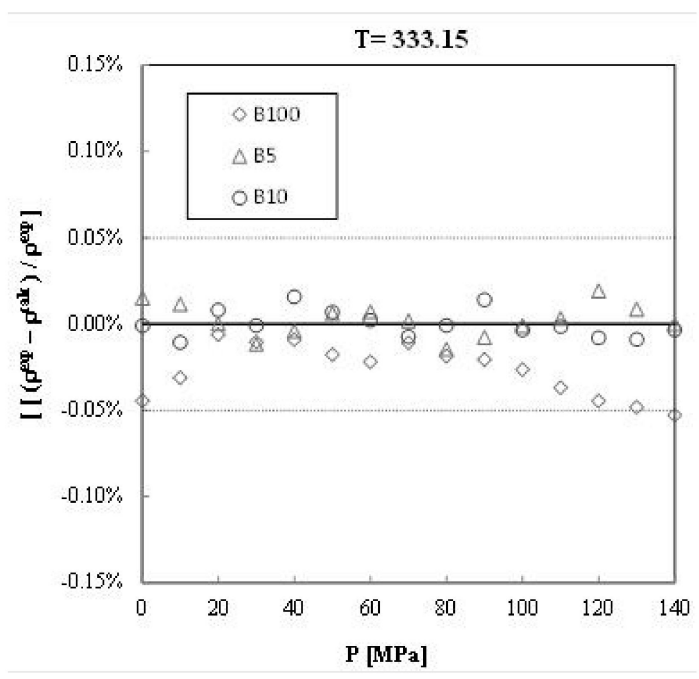

(b)

Figure 7. Relative deviations between experimental data and calculated densities using the Tait equation as a function of pressure at $293.15 \mathrm{~K}$ (a) and $333.15 \mathrm{~K}$ (b) for all samples. The zero line is experimental data.

\subsection{Isothermal Compressibility}

The isothermal compressibility is defined as:

$$
\mathrm{\kappa}_{\mathrm{T}}=\frac{1}{\rho}\left(\frac{\mathrm{d} \rho}{\mathrm{dP}}\right)_{\mathrm{T}}
$$

The values are obtained by analytical differentiation with respect to pressure of Equation (1). Knowing that the original Tait equation is a phenomenological representation of the compressibility versus pressure, the values of $\kappa_{T}$ were obtained by analytical differentiation of Equation (1). This is the most direct way to get reliable values of the isothermal compressibility. The uncertainty is estimated to be lower than $2 \%$, as reported in previous studies [23,24]. As an illustration, in Figure 8 is plotted the variation of $\kappa_{T}$ as a function of pressure (isothermal curves) for the biodiesel. Figure $9 \mathrm{a}, \mathrm{b}$ display the variation of the isothermal compressibility for both the pure biodiesel and its blends.



Figure 8. Variation of WCO biodiesel $\mathrm{K}_{\mathrm{T}}$ as a function of pressure for various temperatures: $293.15 \mathrm{~K}$, 口 $313.15 \mathrm{~K}, \mathbf{\Delta} 333.15 \mathrm{~K}, \times 353.15 \mathrm{~K}$. 


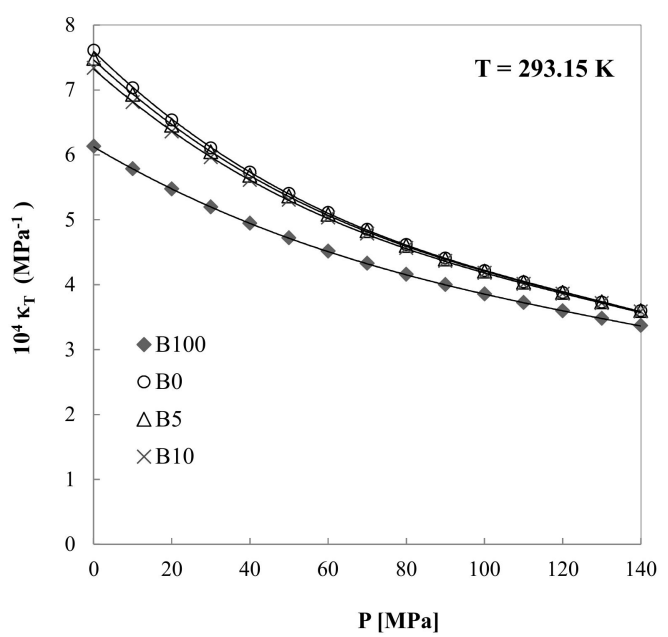

(a)

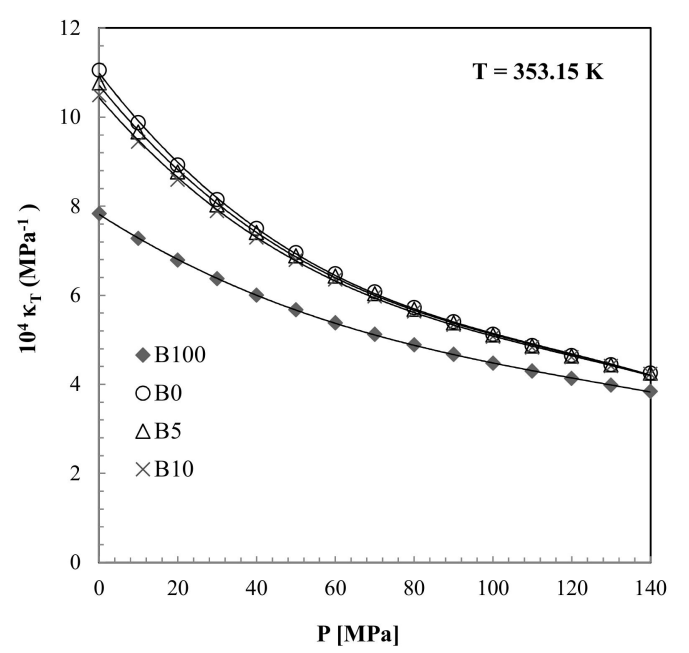

(b)

Figure 9. Variation of $\mathrm{K}_{\mathrm{T}}$ as a function of pressure of biodiesel (B100), pure diesel (B0), and their blends (B5 and B10) at $293.15 \mathrm{~K}(\mathbf{a})$ and at $353.15 \mathrm{~K}(\mathbf{b})$.

A very similar behavior is observed for all the samples. It tends to a constant and common value towards higher pressures. From a theoretical point of view, this behavior already reported should be regarded as a meaningful test to validate the development of models. It also represents useful information for testing and calibrating engine systems.

The raw data of the isothermal compressibility $\mathrm{k}_{\mathrm{T}}$ obtained for the biodiesel, diesel, and its blends (B5 and B10) are listed in Table 5.

Table 5. The raw data of $\kappa_{\mathrm{T}}$ obtained for the WCO biodiesel (B100), pure diesel (B0), and their blends

(B5 and B10).

\begin{tabular}{|c|c|c|c|c|}
\hline & \multicolumn{4}{|c|}{$\mathrm{T}(\mathrm{K})$} \\
\hline & 293.15 & 313.15 & 333.15 & 353.15 \\
\hline P (MPa) & \multicolumn{4}{|c|}{$10^{4} \kappa_{\mathrm{T}}\left(\mathrm{MPa}^{-1}\right)$} \\
\hline \multicolumn{5}{|c|}{ B100 } \\
\hline 0.1 & 6.12791 & 6.48718 & 7.02636 & 7.83080 \\
\hline 10 & 5.78100 & 6.09975 & 6.57421 & 7.27352 \\
\hline 20 & 5.47017 & 5.75489 & 6.17567 & 6.78935 \\
\hline 30 & 5.19265 & 5.44879 & 5.82495 & 6.36858 \\
\hline 40 & 4.94329 & 5.17517 & 5.51383 & 5.99938 \\
\hline 50 & 4.71796 & 4.92906 & 5.23586 & 5.67269 \\
\hline 60 & 4.51330 & 4.70645 & 4.98596 & 5.38148 \\
\hline 70 & 4.32655 & 4.50409 & 4.76002 & 5.12019 \\
\hline 80 & 4.15544 & 4.31930 & 4.55470 & 4.88437 \\
\hline 90 & 3.99803 & 4.14986 & 4.36727 & 4.67043 \\
\hline 100 & 3.85274 & 3.99390 & 4.19546 & 4.47542 \\
\hline 110 & 3.71819 & 3.84985 & 4.03736 & 4.29688 \\
\hline 120 & 3.59322 & 3.71638 & 3.89137 & 4.13280 \\
\hline 130 & 3.47683 & 3.59235 & 3.75614 & 3.98146 \\
\hline 140 & 3.36815 & 3.47678 & 3.63050 & 3.84141 \\
\hline \multicolumn{5}{|c|}{ B0 } \\
\hline 0.1 & 7.61049 & 8.60011 & 9.74224 & 11.04942 \\
\hline 10 & 7.03248 & 7.86956 & 8.81570 & 9.87327 \\
\hline
\end{tabular}


Table 5. Cont.

\begin{tabular}{|c|c|c|c|c|}
\hline & \multicolumn{4}{|c|}{$\mathrm{T}(\mathrm{K})$} \\
\hline & 293.15 & 313.15 & 333.15 & 353.15 \\
\hline $\mathbf{P}(\mathrm{MPa})$ & \multicolumn{4}{|c|}{$10^{4} \kappa_{\mathrm{T}}\left(\mathrm{MPa}^{-1}\right)$} \\
\hline 20 & 6.53495 & 7.25255 & 8.04977 & 8.92402 \\
\hline 30 & 6.10605 & 6.72913 & 7.41149 & 8.14823 \\
\hline 40 & 5.73233 & 6.27928 & 6.87108 & 7.50188 \\
\hline 50 & 5.40366 & 5.88833 & 6.40738 & 6.95472 \\
\hline 60 & 5.11228 & 5.54530 & 6.00497 & 6.48529 \\
\hline 70 & 4.85210 & 5.24179 & 5.65232 & 6.07796 \\
\hline 80 & 4.61831 & 4.97125 & 5.34061 & 5.72102 \\
\hline 90 & 4.40703 & 4.72854 & 5.06304 & 5.40555 \\
\hline 100 & 4.21513 & 4.50950 & 4.81421 & 5.12465 \\
\hline 110 & 4.04002 & 4.31081 & 4.58983 & 4.87285 \\
\hline 120 & 3.87957 & 4.12970 & 4.38642 & 4.64580 \\
\hline 130 & 3.73198 & 3.96393 & 4.20113 & 4.43997 \\
\hline 140 & 3.59574 & 3.81159 & 4.03161 & 4.25249 \\
\hline \multicolumn{5}{|c|}{ B5 } \\
\hline 0.1 & 7.47859 & 8.42162 & 9.51242 & 10.76818 \\
\hline 10 & 6.92808 & 7.73026 & 8.64008 & 9.66432 \\
\hline 20 & 6.45196 & 7.14291 & 7.91387 & 8.76612 \\
\hline 30 & 6.03980 & 6.64217 & 7.30517 & 8.02721 \\
\hline 40 & 5.67939 & 6.20998 & 6.78728 & 7.40824 \\
\hline 50 & 5.36144 & 5.83303 & 6.34108 & 6.88188 \\
\hline 60 & 5.07879 & 5.50122 & 5.95247 & 6.42856 \\
\hline 70 & 4.82579 & 5.20682 & 5.61085 & 6.03390 \\
\hline 80 & 4.59795 & 4.94376 & 5.30809 & 5.68707 \\
\hline 90 & 4.39165 & 4.70723 & 5.03783 & 5.37977 \\
\hline 100 & 4.20394 & 4.49336 & 4.79504 & 5.10552 \\
\hline 110 & 4.03237 & 4.29900 & 4.57568 & 4.85919 \\
\hline 120 & 3.87494 & 4.12156 & 4.37648 & 4.63668 \\
\hline 130 & 3.72993 & 3.95890 & 4.19474 & 4.43465 \\
\hline 140 & 3.59592 & 3.80922 & 4.02823 & 4.25035 \\
\hline \multicolumn{5}{|c|}{ B10 } \\
\hline 0.1 & 7.33483 & 8.26828 & 9.32096 & 10.48672 \\
\hline 10 & 6.80990 & 7.60755 & 8.49014 & 9.44723 \\
\hline 20 & 6.35397 & 7.04369 & 7.79480 & 8.59544 \\
\hline 30 & 5.95785 & 6.56113 & 7.20938 & 7.89066 \\
\hline 40 & 5.61037 & 6.14327 & 6.70945 & 7.29748 \\
\hline 50 & 5.30298 & 5.77778 & 6.27735 & 6.79103 \\
\hline 60 & 5.02904 & 5.45527 & 5.89998 & 6.35339 \\
\hline 70 & 4.78330 & 5.16849 & 5.56746 & 5.97125 \\
\hline 80 & 4.56158 & 4.91175 & 5.27214 & 5.63457 \\
\hline 90 & 4.36046 & 4.68051 & 5.00802 & 5.33559 \\
\hline 100 & 4.17718 & 4.47109 & 4.77036 & 5.06823 \\
\hline 110 & 4.00942 & 4.28050 & 4.55532 & 4.82768 \\
\hline 120 & 3.85528 & 4.10629 & 4.35976 & 4.61003 \\
\hline 130 & 3.71312 & 3.94641 & 4.18113 & 4.41213 \\
\hline 140 & 3.58160 & 3.79912 & 4.01729 & 4.23136 \\
\hline
\end{tabular}

\section{Conclusions}

The density of a biodiesel produced from waste cooking oil and of two of its diesel blends was experimentally investigated over broad ranges of pressure and temperature. To the best of our knowledge, this is the first set of experimental data provided for waste cooking oil biodiesel in similar pressure and temperature ranges. 
The main conclusions can be depicted as follows:

- $\quad$ The WCO biodiesel demonstrated high stability as well as suitable cold properties. This is due to its FAMEs profile.

- The density value is somewhat higher that the allowed standards. At $293.15(\mathrm{~K})$ and for high pressures (120-140 MPa), the density seems to be affected by the high viscosity values of the biodiesel.

- $\quad$ Nevertheless, these first results obtained are very promising in view of its transferability at the industrial scale.

- This original set of experimental data measured for waste cooking oil biodiesel could be used to test predictive models developed for biodiesel thermodynamic properties.

Author Contributions: D.B. and T.X.N. conceived and designed the experiments; T.X.N. and J.-P.B. performed the experiments and analyzed the data; D.B. and T.X.N. wrote the paper.

Conflicts of Interest: The authors declare no conflict of interest.

\section{References}

1. Lin, L.; Cunshan, Z.; Vittayapadung, S.; Xiangqian, S.; Mingdong, D. Opportunities and challenges for biodiesel fuel. Appl. Energy 2011, 88, 1020-1031. [CrossRef]

2. Balat, M. Potential alternatives to edible oils for biodiesel production-A review of current work. Energy Convers. Manag. 2011, 52, 1479-1492. [CrossRef]

3. Bhuiya, M.M.K.; Rasul, M.G.; Khana, M.M.K.; Ashwath, N.; Azada, A.K.; Hazrata, M.A. Second Generation Biodiesel: Potential Alternative to Edible Oil-Derived Biodiesel. Energy Procedia 2014, 61, 1969-1972. [CrossRef]

4. Kalam, M.A.; Masjuki, H.H.; Jayed, M.H.; Liaquat, A.M. Emission and performance characteristics of an indirect ignition diesel engine fuelled with waste cooking oil. Energy 2011, 36, 397-402. [CrossRef]

5. Karmee, S.K.; Patria, R.D.; Ki Lin, C.S. Techno-Economic Evaluation of Biodiesel Production from Waste Cooking Oil -A Case Study of Hong Kong. Int. J. Mol. Sci. 2015, 16, 4362-4371. [CrossRef] [PubMed]

6. Montefrio, M.J.F.; Obbard, J.P. The economics of biodiesel derived from waste cooking oil in the Philippines. Energy Sources Part B 2010, 5, 337-347. [CrossRef]

7. Nas, B.; Berktay, A. Energy potential of biodiesel generated from waste cooking oil: An environmental approach. Energy Sources Part B 2007, 2, 63-71. [CrossRef]

8. Sheinbaum-Pard, O.C.; Calderon-Irazoque, A. Ramirez-Suarez, M. Potential of biodiesel from waste cooking oil in Mexico. Biomass Bioenergy 2013, 56, 230-238. [CrossRef]

9. Man, K.L.; Keat, T.L.; Abdul Rahman, M. Homogeneous, heterogeneous and enzymatic catalysis for transesterification of high free fatty acid oil (waste cooking oil) to biodiesel: A review. Biotechnol. Adv. 2010, $28,500-518$.

10. Chhetri, A.B.; Watts, K.C.; Islam, M.R. Waste Cooking Oil as an Alternate Feedstock for Biodiesel Production. Energies 2008, 1, 3-18. [CrossRef]

11. Ndiaye, E.H.I.; Bazile, J.P.; Nasri, D.; Boned, C.; Daridon, J.L. High pressure thermophysical characterization of fuel used for testing and calibrating diesel injection systems. Fuel 2012, 98, 288-294. [CrossRef]

12. Fahd, M.E.A.; Lee, P.S.; Chou, S.K.; Wenming, Y.; Yap, C. Experimental study and empirical correlation development of fuel properties of waste cooking palm biodiesel and its diesel blends at elevated temperatures. Renew. Energy 2014, 68, 282-288. [CrossRef]

13. Yoon, S.H.; Park, S.H.; Lee, C.S. Experimental investigation of the fuel properties of biodiesel and its blends at various temperatures. Energy Fuel 2008, 22, 652-656. [CrossRef]

14. Uzun, B.B.; Kılıç, M.; Özbay, N.; Pütün, A.E.; Pütün, E. Biodiesel production from waste frying oils: Optimization of reaction parameters and determination of fuel properties. Energy 2012, 44, 347-351. [CrossRef]

15. Lagourette, B.; Boned, C.; Saint-Guirons, H.; Xans, P.; Zou, H. Densimeter calibration method versus temperature and pressure. Meas. Sci. Technol. 1992, 3, 699-703. [CrossRef] 
16. Miyake, Y.; Baylaucq, A.; Plantier, F.; Bessières, D.; Ushiki, H.; Boned, C. High-Pressure (up to 140MPa) density and derivative properties of some amines (Pentyl-, Hexyl- and Heptyl-amines) between (293.15 and 353.15) K. J. Chem. Thermodyn. 2008, 40, 836-845. [CrossRef]

17. Pineiro, M.M.; Bessieres, D.; Gacio, J.M.; Saint-Guirons, H.; Legido, J.L. Determination of high-pressure liquid density for n-perfluorohexane and n-perfluorononane. Fluid Phase Equilib. 2004, 220, 127-136. [CrossRef]

18. Leung, D.Y.C.; Guo, Y. Transesterification of neat and used frying oil: Optimization for biodiesel production. Fuel Process. Technol. 2006, 87, 883-890. [CrossRef]

19. Sanli, H.; Canakci, M.; Alptekin, E. Predicting the higher heating values of waste frying oils as potential biodiesel feedstock. Fuel 2014, 115, 850-854. [CrossRef]

20. Knothe, G. “Designer" Biodiesel: Optimizing Fatty Ester Composition to Improve Fuel Properties. Energy Fuels 2008, 22, 1358-1364. [CrossRef]

21. Fu, J.; Hue, B.T.B.; Turn, S.Q. Oxidation stability of biodiesel derived from waste cat fish oil. Fuel 2017, 202, 455-463. [CrossRef]

22. Segovia, J.J.; Fandiño, O.; López, E.R.; Lugo, L.; Martín, M.C.; Fernández, J. Automated densimetric system: Measurements and uncertainties for compressed fluids. J. Chem. Thermodyn. 2009, 41, 632-638. [CrossRef]

23. Troncoso, J.; Bessieres, D.; Cerdeirina, C.A.; Carballo, E.; Romani, L. Automated measuring device of (p,rho,T) data-Application to the 1-hexanol plus n-hexane system. Fluid Phase Equilib. 2003, 208, 241-254. [CrossRef]

24. Troncoso, J.; Bessieres, D.; Cerdeirina, C.A.; Carballo, E.; Romani, L. P rho Tx data for the dimethyl carbonate plus decane system. J. Chem. Eng. Data 2004, 49, 923-927. [CrossRef]

(C) 2018 by the authors. Licensee MDPI, Basel, Switzerland. This article is an open access article distributed under the terms and conditions of the Creative Commons Attribution (CC BY) license (http:/ / creativecommons.org/licenses/by/4.0/). 